\title{
IT-technologies in soil Informatics and Russian agribusiness
}

\author{
Diana Eremina ${ }^{1, *}$ \\ ${ }^{1}$ The State Agrarian University of Northern Zauralye, 625003 Tyumen, Republic Street, 7. Russia,
}

\begin{abstract}
One of the promising areas associated with a large amount of information on the properties, characteristics and classification of soils is soil Informatics. Its appearance has allowed soil scientists, farmers and environmentalists to process data; to model soil processes, to make operational decisions on land use; implement systems to assess fertility, control of technological processes in agriculture. Currently multinational and global information systems are used, which contain data on soil profiles of many countries: European Soil Database, Europe; SOTER, global soil information system and others. Information systems at the national level study the soil characteristics of one country: Australian Soil Resource Information System; National Soil Information System (USA) and others. In order to generalize process and preserve information about soils of Russia accumulated by long-term research, a nationwide Soilgeographical database is being developed in our country. To optimize the agricultural activity of certain regions of the country, regional information systems are developed - Accounting and monitoring of agricultural lands of the Novosibirsk region, geoinformation system of the Tyumen region and others. Modern soil information systems, for the most part, are implemented through the use of the GeoRSS standard, which is based on a hypertext providing information on the Internet.
\end{abstract}

\section{Introduction}

Soil is one of the most important, valuable and significant resources for mankind. It allows you to create strategic food reserves of the country. The effectiveness of the use of land resources depends on the knowledge of the peculiarities of soil formation in the regions, the properties and modes of modern soils. Agricultural scientists, land cadastre engineers, agricultural scientists set a priority goal - to develop a system of fertility assessment and study of technological processes that ensure the rational use of soils involved in the arable Fund of the country. One of the main conditions is the extended reproduction of fertility.

The basis of any management is information as one of the most important resources of the company's development. This is especially true for the soil resources of Russia, since its territory is located in almost all natural and climatic zones, each region has its own climatic characteristics, relief, soil-forming rocks. Together it forms a set of types and varieties of

\footnotetext{
*Corresponding author: soil-tyumen@yandex.ru
} 
soils differing in fertility level and possibility of its reproduction [1]. The ability to organize the collection, storage, processing and analysis of information to extract it for optimal decision in the field of national economy and soil science in particular - becomes a priority.

The level of computerization of society allowed to introduce the latest scientific achievements, modern information technologies in all spheres of activity for the solution of problems of the reasonable organization of data, and also their safety. The accelerator of scientific and technological progress is designed to become Informatics - a General scientific discipline that studies the theory and practice, technology and information support for the needs of society, and, in particular, the creation of automated systems for the collection, storage, processing and transmission of information [2].

An important component of computer science is the development of automated information technologies based on the use of computers. Information technologies (IT) provide an opportunity to receive information about soils on a daily basis and process it in real time [3].

All this allowed to combine and widely use in soil science tools and methods of mathematical statistics, modeling, geoinformation systems (GIS) and databases (DB). Practical application of the above-mentioned technologies and methods was found in the system of precision farming, the essence of which is the use of computer and software to optimize technological processes in agriculture and the rational use of arable land, elementary areas of which are characterized by soil heterogeneity [4]. The presence of appropriate databases and powerful computers allows, using mathematical and optimization models, to regulate the mineral nutrition of plants, to create artificial soils with specified fertility characteristics [5].

The purpose of researches. Analyze the created and developing information systems (IS) in the field of soil science at the multinational, national and regional levels.

\section{Materials and Methods}

The Study includes the following types of analysis available in the world and domestic agribusiness information technologies, laid the basis for the historiographical, comparative, system and historical methods. The elements of simulation modeling for forecasting the development of it-technologies in the field of agribusiness are also used.

\section{Results and discussion}

Currently there are several dozen regional systems, more than 10 soil of IS at the national level (Australian Soil Resource Information System; National Soil Information System (USA) etc.), and a few more multinational and global systems (European Soil Database, Europe; SOTER, global soil is, etc.).

The world community recommends a Digital database of Soils and Land as an international (Soil and Terrain Digital Data Base) - Soter, ideas for the creation of which were put forward in 1986 in the Netherlands. The main objective of the Soter project is to introduce the technology of accurate and important data collection for the creation of a global database on soils and land in order to improve the processes of soil and land resources inventory, monitoring their changes [6]. For today, most of the existing soil IS performed according to the SOTER methodology (Fig. 1). 


\section{Soil and Terrain Database for Central Africa (SOTERCAF)}

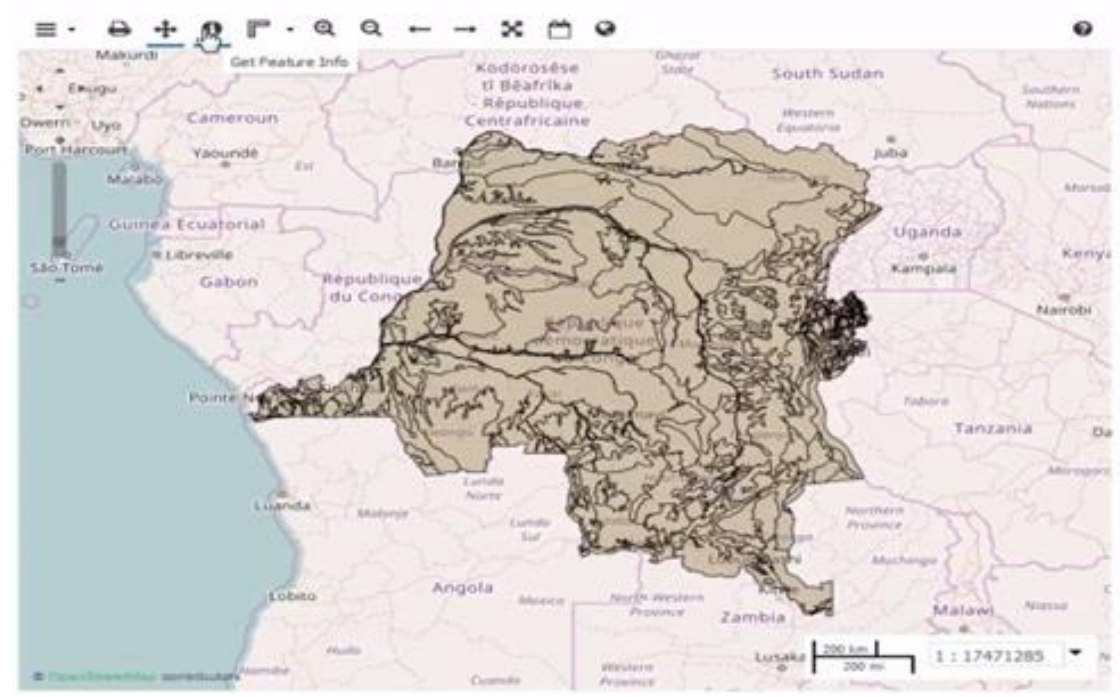

Fig. 1. Window information system of the SOTER

The Australian Soil Resource Information system (ASRIS) provides online access to information on soil and land resources in a consistent format across Australia. The data are located on seven levels: on the top three - a description of soils, landscapes of the continent; on the three averages - describes the properties of soils; on the bottom - a separate site with a database. Information system allows you to go to a specific interesting theme - nutrient management, crop-modelling, etc. Access to the geographic information system ASRIS is through the Internet (Fig.2). When setting the parameters of the subject area, the data is recorded on the layers of the map, if there is many data, cluttered maps at viewing can significantly reduce the performance of computer equipment [7].

Analysis of the market of information systems in the field of soil science shows that foreign soil information systems are developing very quickly and dynamically.

Russian soil scientists have made a significant contribution to the development of common ideas for building soil automation systems. At the same time, there is still no actual functioning soil Information System in Russia, so one of the most important tasks is to create an actual domestic system. In Russia, it is long overdue to create a soil profile information database corresponding to the world level, which should become the basis for the creation of a system of soil monitoring and the development of measures for their protection and rational use $[8,9]$. 


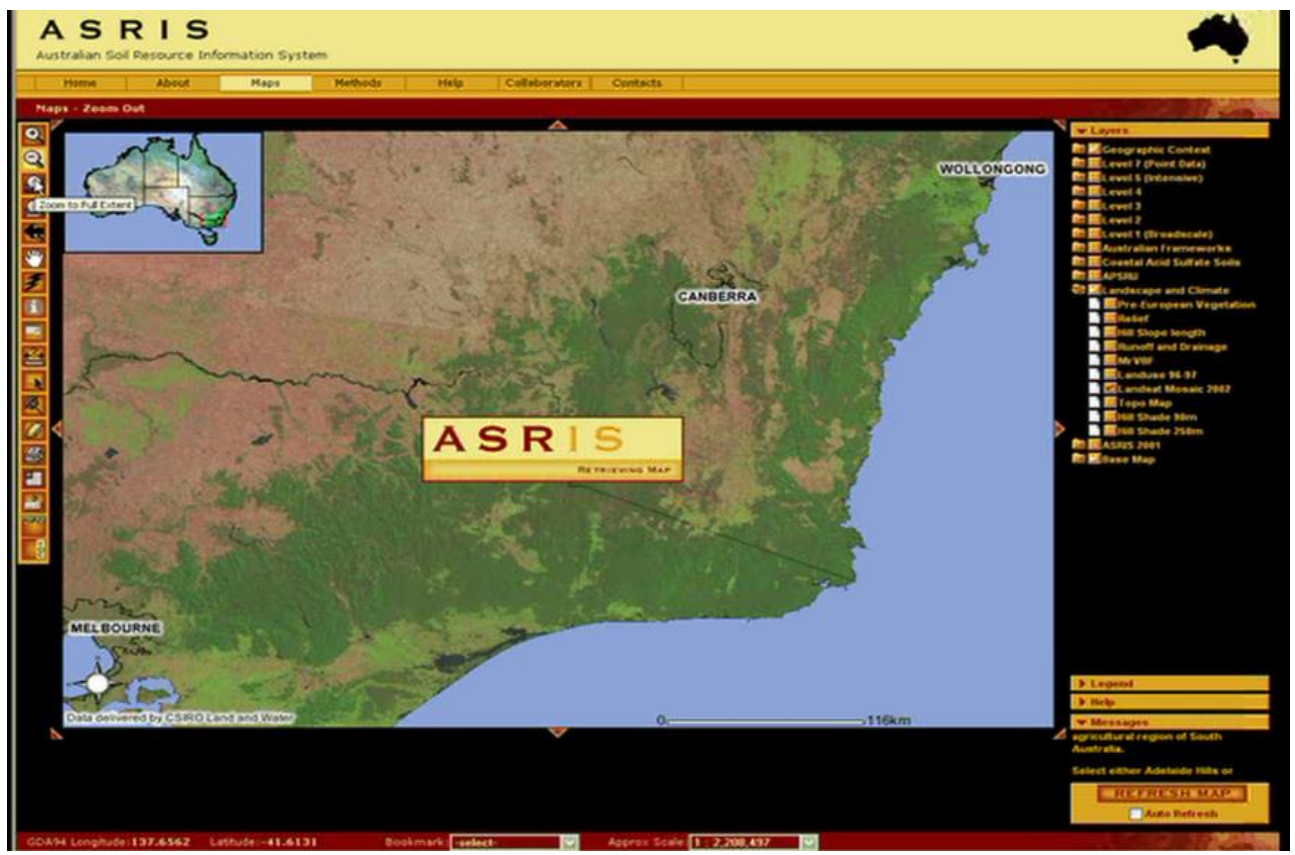

Fig. 2. Dialog information system ARIS

The first national soil information system (ASIS) "Podzol"; "Ararat"; "AIS Meron" was created in the Soil Institute named after V. V. Dokuchaev under the leadership of V. A. Rozhkov [12]. Work has begun on the creation of a national Soil geographic database (SGDB) [8] since 2008 on the initiative of the all-Russian society of soil science named after V. V. Dokuchaev of employeesgroup of the Department of soil science of MSU named after M. V. Lomonosov and Soil Institute of the V.V. Dokuchaev. The purpose is the collection, processing and storage of huge information arrays about the soils of Russia, accumulated by years of research.

Currently, a Unified state register of soil resources of Russia has been prepared and published, including a description of soils, soil resources of the RF subjects, soil-ecological zoning and a digital model of soil data description. The result of the local DBMS (format MS access of hierarchical structure) is a structured description of one or more soil profiles. The information system allows you to analyze stored information using query forms. This is implemented in SGDB of the Russian Federation due to the application of the GeoRSSstandard, based on a hypertext providing information on the Internet. This approach was tested and put into trial operation for Matveevo-Kurgan district of Rostov region [9]. The principles of the GeoRSS construction in our country reflected in other subject areas, so the SGDB of Russian Federation can be called "first swallow".

Information and reference system for soil classification INFOSOIL (Fig.3) (http://infosoil.ru/) shows the structure of the classifications of soils; provides descriptions of the types and subtypes of soils and synonymy of their names with some other classification systems; solves the problem of recognition of new soil at a predetermined level of similarity with the system described in [9].

In Western Siberia, regional information systems are being developed to classify and process soil data. The main idea is not new-to create a database that combines data on soils of a particular region. For the Siberian region, this type of work is most relevant, since there is no detailed information about the properties and morphogenetic characteristics of soils. 
Especially it is very little information on anthropogenically transformed, technogenicdisturbed soils $[10,11,12]$.

Employees of the Institute of soil science and Agrochemistry (Novosibirsk) together with the Soil Institute named after V. V. Dokuchaev carried out work on the creation of a hierarchical database on saline soils of Russia on the basis of geoinformation technologies, remote sensing data and database management systems [13].

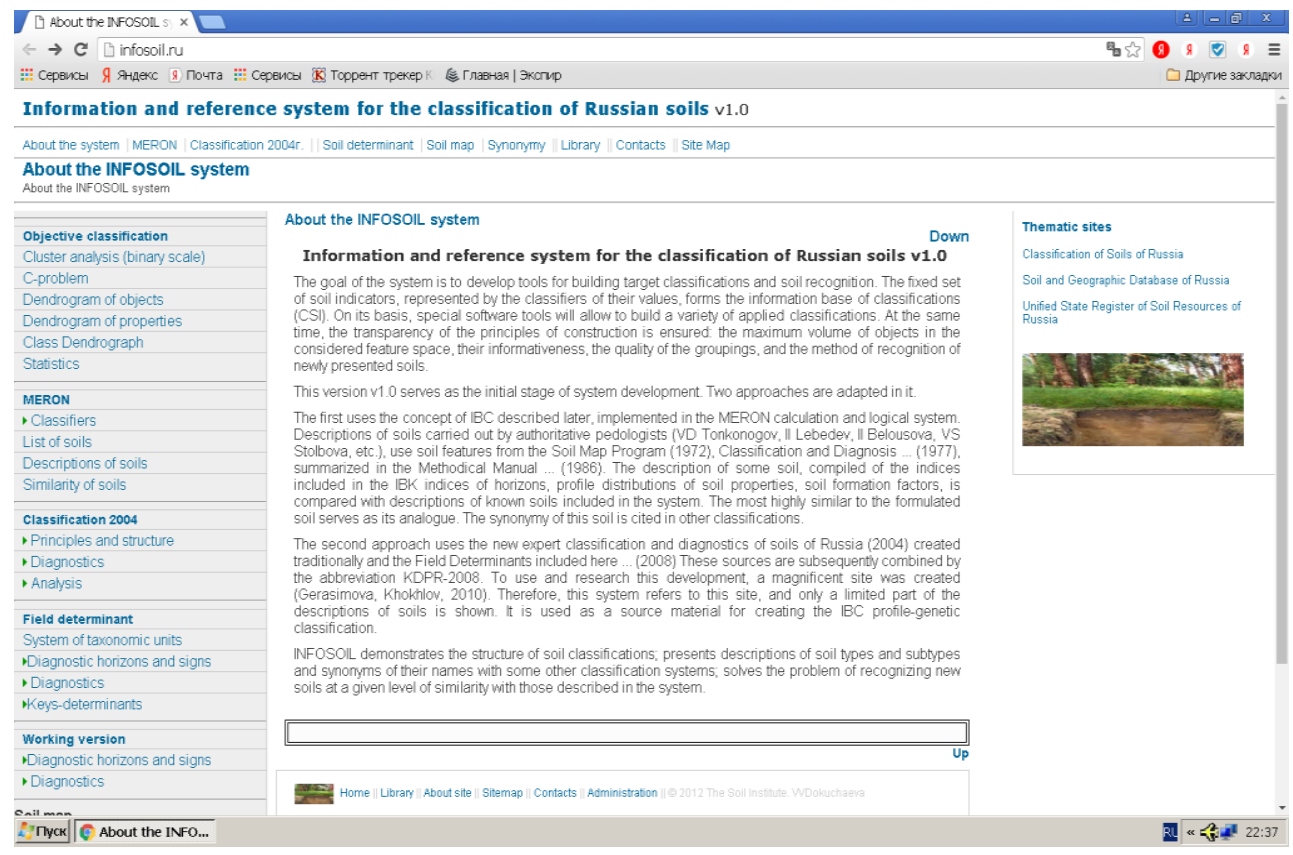

Fig. 3. Window reference system INFOSOIL

Implementation of the automated information system "Accounting and monitoring of agricultural lands of the Novosibirsk region" (AIS AM ACL NR) will allow to keep records and monitoring of agricultural lands by the main characteristics of soils, cultivated crops; to monitor and plan the activities of tenants or owners.

Geoinformation systems and technologies for automated processing of space images take into account both quantitative and qualitative indicators of soil cover structure. This is stated in the works of Pavlova A. I. (Siberian state Academy of geodesy, Novosibirsk), Kubasov, A.V., Nagibin A. G. (Siberian research Institute of agriculture, Omsk). The involvement of pattern-recognition methods of space images and GIS made it possible to characterize soil combinations according to their belonging to a certain genetic and geometrical shape, mode of occurrence in the topography, quantitative indicators.

The project of the information system of soils of Krasnoyarsk region, which is planned to be developed jointly with the SFU, will be implemented on the basis of open source programs. The purpose of the project is to quickly find and obtain the necessary data on the soils of the Krasnoyarsk territory (in the future, it is also possible for other regions) for carrying out various studies related to soils.

Geoinformation system of the Tyumen region (Geoportal opened on 13 January 2015) is a set of map services that allow users to access regional spatial data stored in information systems of the Executive bodies of state power of the Tyumen region. Due to the convenient and modern interface, citizens and organizations have access to relevant and reliable information presented on different thematic layers. 
Since 2018, a program of total digitization of fields and other land uses will be launched in the South of the Tyumen region. This will make it possible to rationalize the use of agricultural land, to control the fertility of arable land, to obtain timely information about the owners and tenants of plots. This global work has been made possible only with the development of computers and information technology. The next year (2018) may be the year of birth of soil Informatics in the Tyumen region.

\section{The conclusion}

After reviewing the existing soil information systems at the international, national and regional levels, the role of soil Informatics in IT technologies of modern agribusiness was established. The theoretical significance is due to the interest of scientists engaged in paedogenesis and soil ecology.From the practical point of view; soil information systems are extremely relevant. They provide an opportunity to optimize technological processes in agriculture. IT-technologies are capable to carry out constant monitoring of fertility and ecological condition of soils, to rationalize their use.

\section{References}

1. N.P. Odgers, A.B. McBratney, B. Minasny, Geoderma. 163, 30-44 (2011)

2. E.P. Renev, D.I. Eremin and D.V. Eremina, Advances in science and technology AIC. 31(4), 27-31 (2017)

3. J. H. Huddleston, Geoderma. 32(4), 297-317 (1984), doi:10.1016/00167061(84)90009-0

4. D.I. Eremin, Yu. P. Kibuk, Bulletin of the Krasnoyarsk state agrarian University. 8(131), 17-26 (2017)

5. D.I. Eremin, Eurasian Soil Science. 49(5), 538-545 (2016), DOI: $10.1134 / \mathrm{S} 1064229316050033$

6. G. W. Petersen, G. C. Bell, K. McSweeney, G. A. Nielsen and P. C. Robert, Advances in Agronomy. 55, 67-111 (1995), doi:10.1016/S0065-2113(08)60538-6

7. R. M. Johnston, S. J. Barry, E. Bleys, E. N. Bui, C. J. Moran, D. A. P. Simon, P. Carlile, N. J. McKenzie, B. L. Henderson, G. Chapman, M. Imhoff, D. Maschmedt, D. Howe, C. Grose, N. Schoknecht, B. Powell and M. Grundy, Australian Journal of Soil Research. 41(6), 1021-1036 (2003)

8. V.M. Kolesnikova, I.O. Alyabina, L.A. Vorob'eva, E.N. Molchanov, S.A. Shoba, V.A. $\begin{array}{lllll}\text { Rozhkov, Eurasian Soil Science. 43(8), 839-847 (2010), } & \end{array}$ DOI: $10.1134 / \mathrm{S} 1064229310080016$

9. O.M. Golozubov, V.A. Rozhkov, I.O. Alyabina, A.V. Ivanov, V.M. Kolesnikova, S.A. Shoba, Eurasian Soil Science. 48(1), 1-10 (2015), DOI: 10.1134/S1064229315010068

10. D.I. Eremin, D.V. Eremina, Procedia Engineering. 165, 788-793 (2016), DOI: $10.1016 /$ j.proeng.2016.11.776

11. D.I. Eremin, D.V. Eremina, MATEC Web Conf. 106, 01044 (2017), DOI:10.1051/matecconf $/ 201710601044$

12. D.I. Eremin, IOP Conference Series: Earth and Environmental Science. 90, 12021 (2017), doi.org/10.1088/1755-1315/90/1/012021

13. J.K. Ord, A. Getis, Journal of Regional Science. 41, 411-432 (2001) 